\title{
Avaliação de Modelos de Cálculo de Exigência de Capital para Risco Cambial
}

\author{
Claudio H. da S. Barbedo* \\ Gustavo S. Araújo*** \\ João Maurício S. Moreira*** \\ Ricardo S. Maia Clemente*****
}

\begin{abstract}
Resumo
Neste artigo são avaliados modelos de determinação de exigência de capital de instituições financeiras para cobertura de risco de mercado decorrente de exposição cambial. Os modelos estão divididos em dois grupos, de acordo com a abordagem: padronizada ou de modelos proprietários. No primeiro, são considerados o modelo padronizado de Basiléia e o modelo adotado pela legislação brasileira. No segundo grupo encontram-se os modelos baseados em VaR. São considerados o modelo histórico, com uma e duas janelas móveis, o modelo de VAR-COV com alisamento exponencial e uma abordagem híbrida que combina características de ambos. Os resultados sugerem que o modelo padronizado de Basiléia é inadequado à realidade brasileira, apresentando grande número de perdas superiores à exigência de capital. O modelo da legislação brasileira não apresenta exceções, mas gera maiores requerimentos de capital que os modelos baseados em $\mathrm{VaR}$, os quais, a despeito da menor exigência de capital, apresentam, em geral, desempenhos adequados.
\end{abstract}

\begin{abstract}
This paper examines models of capital requirement for financial institutions in order to cover market risk stemming from exposure to foreign currencies. The models examined belong to two groups according to the approach involved: standardized and internal models. In the first group, we study the Basel model and the model adopted by the Brazilian legislation. In the second group, we consider the models based on the concept of value at risk (VaR). We analyze the single and double-window historical model, the exponential smoothing model (EWMA) and a hybrid approach that combines features of both models. The results suggest that the Basel model is inadequate to the Brazilian market, exhibiting a large number of exceptions. The model of the Brazilian legislation has no exceptions, though generating higher capital requirements than other internal models based on VaR. In general, VaR-based models perform better and result in less capital allocation than the standardized approach model applied in Brazil.
\end{abstract}

\footnotetext{
Submetido em Novembro de 2004. Revisado em Janeiro de 2006.

*Departamento de Estudos e Pesquisas do Banco Central do Brasil. E-mail: claudio.barbedo@bcb.gov.br

**Departamento de Estudos e Pesquisas do Banco Central do Brasil. E-mail: gustavo.araujo@bcb.gov.br

***Departamento de Estudos e Pesquisas do Banco Central do Brasil. E-mail: joao.mauricio@bcb.gov.br

****:Departamento de Estudos e Pesquisas do Banco Central do Brasil.

E-mail: ricardo.maia@bcb.gov.br
} 
Palavras-chave: exigência de capital; acordo de Basiléia; risco de mercado; VaR; risco cambial.

Códigos JEL: E58; G18; G28.

\section{Introdução}

Em 1996, o Comitê da Basiléia divulgou um conjunto de propostas que procura fornecer às autoridades de supervisão bancária nacionais as diretrizes básicas para a regulamentação da exigência de capital para cobertura do risco de mercado. ${ }^{1}$ As propostas sugerem, para efeito de alocação de capital regulatório de uma instituição financeira, duas alternativas básicas de cálculo: a abordagem padronizada e a abordagem baseada em modelos internos de gestão de risco. Os bancos que cumprem determinados requisitos podem calcular sua própria exigência de capital com base em certos parâmetros determinados pela autoridade monetária. Os demais estariam sujeitos aos requerimentos impostos pela abordagem padronizada.

O requerimento de capital calculado por meio da abordagem padronizada, conforme a estrutura proposta pelo Comitê de Basiléia, tende a ser superior àquele que resultaria de um modelo interno, mais adequado ao perfil de risco de cada instituição. Dessa forma, haveria um estímulo, expresso em redução de exigência de capital, para que as instituições financeiras desenvolvessem sistemas de gerenciamento de risco mais precisos.

A abordagem padronizada caracteriza-se pela ausência de sensibilidade a alterações nos padrões de volatilidade e nas correlações dos fatores de risco. Esta é uma limitação importante, principalmente em se tratando de mercados sujeitos a oscilações consideráveis nos preços de seus ativos, como o brasileiro. ${ }^{2}$

A abordagem baseada em modelos internos permite que as instituições financeiras utilizem modelos de risco próprios. Com a finalidade de assegurar um grau mínimo de padronização e consistência dos resultados obtidos para os diferentes sistemas proprietários, foram estabelecidas algumas restrições qualitativas e quantitativas, destacando-se entre estas últimas o cômputo do valor em risco (VaR) diário, o horizonte de investimento (holding period) de dez dias, o nível de confiança de $99 \%$ e o fator multiplicador mínimo de três.

Considerando que os padrões de volatilidade no mercado brasileiro variam fortemente, em comparação aos mercados do G-10, e que isto aliado aos parâmetros definidos pelo Comitê da Basiléia possa levar a exigências de capital exageradas em alguns períodos, busca-se adaptar a fórmula de modelos internos a este ambiente com o uso de um fator multiplicador menor. Além disso, em se tratando de mercados emergentes, sujeitos a fortes e freqüentes oscilações dos padrões de volatilidade, é importante avaliar criteriosamente o desempenho dos modelos não

\footnotetext{
${ }^{1}$ Ver Basel Committee on Banking Supervison (1996a).

${ }^{2}$ Vale observar que, para taxas de juros prefixadas, o Banco Central do Brasil adota um critério padronizado com características de modelo interno ao utilizar o $\mathrm{VaR}$ e, por conseqüência, considerar alterações na volatilidade do mercado. Ver Banco Central do Brasil (2000).
} 
somente com relação ao VaR, como sugere o Acordo da Basiléia, mas também em relação à própria exigência de capital.

O Banco Central do Brasil regulamentou as exigências de capital para cobertura de risco de mercado decorrente da exposição nos instrumentos referenciados em câmbio e em ouro adotando a abordagem padronizada, não sendo facultado às instituições financeiras o uso de modelos internos para o cálculo do encargo de capital. $^{3}$

Este artigo objetiva avaliar cinco modelos de determinação da exigência de capital para a cobertura de risco de mercado em moedas estrangeiras e em ouro com dados do mercado brasileiro, buscando subsidiar as discussões que envolvem a regulamentação da matéria no país. Os dois primeiros modelos seguem a abordagem padronizada. São avaliados o modelo padronizado de Basiléia e o modelo adotado pela legislação brasileira, em duas versões: antes e depois da alteração que permite a compensação entre posições opostas em dólar dos Estados Unidos, euro, libra esterlina, iene, franco suíço, implementada pela Circular 3.217, de 19 de dezembro de 2003, posteriormente substituída pela Circular 3.229, de 25 de março de 2004, que estende ao ouro a possibilidade de compensação. ${ }^{4}$ Os demais, inseridos na abordagem de modelos internos, são: o modelo histórico, com uma e duas janelas móveis; o modelo baseado em alisamento exponencial; e o modelo histórico híbrido, que combina características dos dois anteriores.

Os resultados mostram um fraco desempenho do modelo padronizado de Basiléia, que apresenta um grande número de exceções devido às flutuações da volatilidade no mercado brasileiro, em conjunto com um requerimento de capital reduzido. O modelo da legislação brasileira não apresenta exceções, mas gera, em média, maiores requerimentos de capital que os modelos baseados em VaR, mesmo levando em conta a alteração estabelecida pela Circular 3.229. Como esperado, os modelos baseados em VaR apresentam bom desempenho, mesmo com menores alocações de capital que o modelo padronizado em vigor no Brasil.

O restante deste trabalho está assim organizado: a próxima seção descreve os dados utilizados e a metodologia empregada na construção e na avaliação dos modelos de cálculo exigência de capital; a terceira seção apresenta os resultados obtidos; e a quarta e última seção reúne as conclusões e considerações finais.

\section{Amostra e Metodologia}

\subsection{Amostra}

As séries utilizadas na composição das carteiras consistem nas cotações de dólar norte-americano, euro, libra esterlina, yen, franco suíço e ouro, no período de 4/1/2000 a 25/7/2003. A data inicial foi escolhida em função do início de circulação do euro. Vale observar que, embora relativamente curto, o período con-

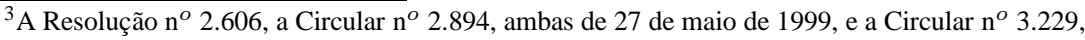
de 25 de março de 2003, são os principais normativos da matéria.

${ }^{4}$ Ver Banco Central do Brasil (2003b) e Banco Central do Brasil (2004), respectivamente.
} 
siderado engloba eventos que levaram a flutuações significativas da volatilidade do câmbio, o que permite a avaliação dos modelos considerados em situações de estresse do mercado. ${ }^{5}$ A Figura A.1 mostra o comportamento da volatilidade dos retornos da cotação do dólar americano em reais, no período de 01/03/2000 a $25 / 7 / 2003$, estimada com base no procedimento de alisamento exponencial. ${ }^{6}$

\section{Organização das carteiras}

São construídas seis carteiras com base em diferentes combinações dos ativos, com o objetivo de reproduzir situações que possibilitem a aferição dos modelos em níveis diversos de risco. As carteiras se encontram detalhadas na Tabela A.1.

A carteira 1 é composta unicamente pela moeda estrangeira mais negociada no Brasil, o dólar norte-americano. A carteira 2 se caracteriza por posições opostas em dólar norte-americano e em euro, possibilitando a avaliação da compensação entre moedas, para efeito de requerimento de capital. A carteira 3 combina posições compradas ou vendidas em todas as moedas. A carteira 4 reúne as moedas que apresentaram o maior valor de correlação linear para as séries estudadas, o euro e o franco suíço, em posições opostas. É incluída ainda uma posição vendida em ouro. A carteira 5 é composta novamente por dólar norte-americano e euro, desta vez ambos em posições compradas, em conjunto com uma posição vendida em ouro. A última carteira é composta unicamente pelo yen, o ativo que apresenta, dentre os considerados, o maior desvio-padrão no período estudado. Todas as carteiras são consideradas também em sua versão simétrica.

\section{Cálculo das séries de retornos}

O retorno de um ativo financeiro é dado por $R_{t}=\ln \left(p_{t} / p_{t-1}\right)-1$, onde $p_{t}$ corresponde à cotação de venda de fechamento da moeda na data $t .^{7}$ Para o modelo de cálculo do VaR baseado em alisamento exponencial, utilizamos a sua aproximação pela forma logarítmica, $r_{t}=\ln \left(p_{t} / p_{t-1}\right)$, onde denota o logaritmo neperiano. 8

\subsection{Modelos de determinação de exigência de capital}

São avaliados cinco modelos de determinação da exigência de capital para fazer face ao risco de mercado incorrido por posições assumidas em moedas estrangeiras e em ouro. Sob o enfoque da abordagem padronizada, o primeiro modelo segue a abordagem do Acordo da Basiléia, enquanto o segundo consiste na regulamentação brasileira, em duas versões: antes e depois da alteração que permite a compensação entre posições opostas em dólar dos Estados Unidos, euro,

\footnotetext{
${ }^{5}$ Crise da Argentina, crise energética e, marcadamente, o período de sucessão presidencial.

${ }^{6}$ Todas as figuras e tabelas encontram-se no anexo, ao final do artigo.

${ }^{7}$ Cotação de fechamento Ptax, calculada como a taxa média ponderada dos negócios realizados no mercado interbancário de câmbio, calculada pelo Banco Central do Brasil, conforme Comunicado 6.815 de 28 de junho de 1999.

${ }^{8}$ Adota-se a hipótese de lognormalidade das cotações cambiais para este modelo.
} 
libra esterlina, iene, franco suíço e ouro. Os demais modelos, histórico, de VARCOV com alisamento exponencial e histórico híbrido, se inserem na abordagem de modelos internos, cuja exigência de capital (EC), para cada dia t, é calculada por: 9

$$
E C_{t}=\max \left\{\left(\frac{M}{60} \sum_{k=1}^{60} V a R_{t-k+1}^{10 d}\right), V a R_{t}^{10 d}\right\}
$$

onde $M$ é o multiplicador da média do VaR para dez dias $\left(V a R_{t}^{10 d}\right)$ dos últimos sessenta dias. $\mathrm{O}$ valor de $M$ é inicialmente estabelecido em 3 no Acordo da Basiléia, podendo chegar a 4, de acordo com o desempenho do modelo utilizado pela instituição financeira. Considerando que os padrões de volatilidade no mercado brasileiro variam fortemente, em comparação aos mercados do G-10, e que isto aliado a $M=3$ possa levar a exigências de capital exageradas em alguns períodos, avalia-se adicionalmente a $E C$ calculada com $M=2$. O VaR é calculado com um nível de confiança de $99 \%$, para as caudas esquerda (posição comprada na carteira) e direita (posição vendida na carteira) das distribuições de retornos das carteiras.

\section{Modelo padronizado de Basiléia}

O critério adotado por Basiléia para a abordagem padronizada de alocação de capital para cobertura de risco cambial prevê uma exigência de capital igual a $8 \%$ do valor da posição aberta líquida total da instituição em moedas estrangeiras e em ouro, a qual é determinada em duas etapas. Na primeira etapa a instituição calcula sua posição líquida em cada uma das moedas com que negocia (inclusive ouro), incluindo o valor das posições à vista e a termo e o valor referente aos contratos de opções, calculado pelo delta da opção multiplicado pela quantidade e pelo tamanho do contrato.

A segunda etapa consiste em converter os valores líquidos, comprados ou vendidos, nas diversas moedas, para a moeda em que a instituição deve apresentar seus relatórios. Estes valores líquidos devem ser somados separadamente, de modo a se obter, no final, dois valores totais: um comprado e outro vendido. O maior destes dois valores, em módulo, é então somado com o módulo da posição líquida em ouro. $\mathrm{O}$ valor obtido corresponde à posição líquida aberta total da instituição em moeda estrangeira.

\section{Modelo da resolução 2.606 de 27 de maio de 1999}

A Resolução 2.606, de 27 de maio de 1999, e a Circular 2.894, de mesma data, formam a base normativa adotada no Brasil até 18 de dezembro de 2003 para a determinação de exigência de capital para cobrir o risco de mercado em operações que gerem exposição em ativos e passivos referenciados em moedas estrangeiras e em ouro. ${ }^{10}$ Neste período, alguns normativos promoveram ajustes em fatores que compõem o cálculo do capital requerido, sendo a última mudança efetivada pela

\footnotetext{
${ }^{9}$ Basel Committee on Banking Supervison (1996b).

${ }^{10}$ Ver Banco Central do Brasil (1999a) e Banco Central do Brasil (1999b), respectivamente.
} 
Circular 3.194, de 2 de julho de 2003, que reduz o fator $F^{\prime \prime}$ (ver definição adiante) de 1 para $0,5 .{ }^{11}$ Contudo, a regra de obtenção da base de cálculo do requerimento de capital permaneceu inalterada.

A Circular 3.217, de 19 de dezembro de 2003, por sua vez, introduziu uma alteração mais profunda nos procedimentos até então adotados ao modificar substancialmente a forma de cômputo da base de cálculo, permitindo a compensação parcial entre posições opostas em dólar norte-americano, euro, libra esterlina, iene e franco suíço. A Circular 3.217 viria a ser revogada pela Circular 3.229, de 25 de março de 2004, que estende a possibilidade de compensação ao ouro.

Desta forma, o modelo da Resolução 2.606, de 27 de maio de 1999, é aqui estudado em duas versões. A primeira, doravante referenciada como versão anterior, reflete a regra em vigor até 18 de dezembro de 2003. A segunda, doravante denominada versão atual, baseia-se na Circular 3.299. Para ambas as versões, o total da exposição é limitado a $30 \%$ do valor do Patrimônio de Referência (PR). ${ }^{12}$

\section{Versão anterior}

Nesta regra, a exposição é definida como a soma, em valor absoluto, das diferenças entre exposições compradas e vendidas, em cada moeda, convertida para o real. Se a exposição for inferior a 5\% do PR, não será exigido capital. Para qualquer exposição superior a $5 \%$ do PR, será exigido um aporte adicional de capital (ao Patrimônio Líquido Exigido - PLE) equivalente a 50\% do total da exposição $\left(F^{\prime \prime}=0,5\right)$. Analiticamente, a exigência de capital (EC) é dada por:

$$
E C=F^{\prime \prime} \times \max \left\{\left(\sum_{i=1}^{n}\left|L_{i}\right|-k \times P R\right) ; 0\right\}
$$

onde $E C=$ Exigência de capital;

$F^{\prime \prime}=0,5$ é o fator aplicável àquelas operações; $\sum_{i=1}^{n}\left|L_{i}\right|$ é o somatório dos valores absolutos das posições líquidas em cada moeda e ouro;

$$
\begin{gathered}
k=5 \% \text { se } \sum_{i=1}^{n}\left|L_{i}\right|<5 \% \text { do } P R \text { e } k=0 \quad \text { caso contrário; } \\
P R=\text { Patrimônio de referência }
\end{gathered}
$$

\section{Versão atual}

Esta versão resulta da alteração dos artigos $1^{\circ}$ e $2^{\circ}$ da Circular 2.894. Na prática, faculta-se considerar como uma única moeda as exposições em dólar norte-americano, euro, libra esterlina, iene, franco suíço e ouro. Na hipótese de

${ }^{11}$ Ver Banco Central do Brasil (2003b).

${ }^{12}$ O Patrimônio de Referência é definido na Resolução 2.837 de 30 de maio de 2001. 
utilização desta alternativa, deve ser adicionado ao valor total da exposição assim calculada, o menor valor entre as seguintes parcelas, multiplicado pelo fator 0,7 :

- O somatório do valor absoluto, para ouro e cada uma das moedas estrangeiras acima relacionadas, do excesso da exposição comprada em relação à exposição vendida;

- O somatório do valor absoluto, para ouro e cada uma das moedas estrangeiras acima relacionadas, do excesso da exposição vendida em relação à exposição comprada;

Analiticamente, a exigência de capital é dada por

$$
E C=F^{\prime \prime} \max \{(E X P-k \times P R) ; 0\}
$$

onde $E C$ Exigência de capital;

$F^{\prime \prime}=0,5$ é o fator aplicável àquelas operações;

$E X P=T_{1}+\alpha \times T_{2}+T_{3}$, correspondendo ao valor total da exposição em ouro e moedas estrangeiras;

$T_{1}=\left|\sum_{i=1}^{n l}\left(\operatorname{Exp} C_{i}-\operatorname{Exp} V_{i}\right)\right|$, em que $E x p C_{i}$ é a exposição comprada, $E x p V_{i}$ é a exposição vendida no i-ésimo ativo e $n 1$ se refere ao grupo de ativos selecionados, composto por dólar norte-americano, euro, yen, libra esterlina, franco suíço e ouro. $\alpha=0,7$ é o fator de hedge relativo aos ativos selecionados;

$$
\begin{gathered}
T_{2}=\min \left[\left|\sum_{i=1}^{n l} \max \left(\operatorname{Exp}_{i}-\operatorname{Exp}_{i} ; 0\right)\right| ;\left|\sum_{i=1}^{n l} \min \left(\operatorname{Exp}_{i}-\operatorname{Exp}_{i} ; 0\right)\right|\right] \\
T_{3}=\sum_{i=1}^{n 2}\left|\operatorname{Exp}_{i}-\operatorname{Exp}_{i}\right|
\end{gathered}
$$

em que $\mathrm{n} 2$ refere-se às moedas estrangeiras que não se encontram no grupo de ativos selecionados.

$$
k=5 \% \text { se } E X P<5 \% \text { do } P R \text { e } k=0 \text { caso contrário; }
$$

$$
P R=\text { Patrimônio de referência }
$$

\section{Modelo histórico}

O modelo histórico consiste em se utilizar um dado quantil da série de retornos da carteira como estimativa de VaR. Os retornos da carteira são simulados tendo como base a sua atual composição (participações financeiras dos ativos na carteira) 
e os retornos verificados para os ativos que a compõe, nos últimos n dias (janela móvel de $n$ dias). O retorno da carteira é dado por:

$$
R_{c}=\sum_{i} w_{i} \times r_{i}
$$

em que $r_{i}$ é o retorno diário do ativo $i$ da carteira. Para cada data $t$, os pesos $w_{i}$ refletem as proporções atuais do valor de cada moeda na carteira. O VaR de dez dias, utilizado no cálculo da exigência de capital, é dado pelo produto do VaR de um dia pela raiz quadrada de dez, conforme indicado pelo Comitê da Basiléia. ${ }^{13}$

\section{Modelo histórico com janela única}

Esta é a forma usual do modelo não-paramétrico do quantil empírico, em que se utilizou apenas uma janela móvel de 252 observações, nos quantis de $1 \%$ (cauda esquerda) e de $99 \%$ (cauda direita). Desta forma, o VaR de um dia será dado pelas fórmulas abaixo:

$$
\begin{gathered}
V_{t, \text { comprado }}^{1 d}=V_{i} \times\left|Q_{1 \%, t}^{252}\right| \\
V a R_{t, \text { vendido }}^{1 d}=V_{i} \times\left|Q_{99 \%, t}^{252}\right|
\end{gathered}
$$

em que $V_{i}$ corresponde ao montante da carteira $i$.

\section{Modelo histórico com janela dupla}

Esta variação do modelo histórico, mais conservadora que a versão tradicional, consiste em considerar duas janelas móveis, concomitantemente, para a obtenção do quantil empírico de interesse. As janelas escolhidas são de 126 e 252 dias. Os quantis de $1 \%$ (cauda esquerda) e de $99 \%$ (cauda direita) são extraídos das duas janelas e aquele que for, para cada cauda, o maior em módulo é utilizado no cálculo do VaR das posições comprada e vendida, segundo as fórmulas seguintes:

$$
\begin{aligned}
& \text { VaR } R_{t, \text { comprado }}^{1 d}=V_{i} \times \max \left|Q_{1 \%, t}^{126} ; Q_{1 \%, t}^{252}\right| \\
& V a R_{t, \text { vendido }}^{1 d}=V_{i} \times \max \left|Q_{99 \%, t}^{126} ; Q_{99 \%, t}^{252}\right|
\end{aligned}
$$

\footnotetext{
${ }^{13} \mathrm{~A}$ regra da raiz quadrada pode ser teoricamente justificada para modelos paramétricos que adotem hipóteses tais como retornos normais e i.i.d. Contudo, o Comitê de Basiléia, não faz qualquer distinção desta ordem, possibilitando o uso da regra para qualquer modelo baseado em VaR (ver Basel Committee on Banking Supervision (1996a), seção B4, item c). Uma alternativa seria calcular o VaR de dez dias com base na série de retornos de dez dias. Porém, como o VaR deve ser calculado diariamente para fins de exigência de capital, isto acarretaria em uma série de retornos fortemente autocorrelacionada.
} 


\section{Modelo de VAR-COV com alisamento exponencial}

Este modelo segue a metodologia do Riskmetrics Group (1996), ${ }^{14}$ em que o VaR de cada ativo componente da carteira é obtido parametricamente a partir da sua volatilidade condicional, estimada com base em alisamento exponencial (EWMA). ${ }^{15}$ Desta forma, o VaR para um dia de cada ativo é dado por: ${ }^{16}$

$$
V a R_{i, t}^{1 d}=V_{i, t} \times\left(\exp z_{\alpha \%} \times h_{i, t}-1\right)
$$

em que $z_{\alpha}$ é o quantil da distribuição normal padronizada relativo à probabilidade de estimativa do VaR, no caso $1 \%$, e $h_{i, t}$ é a volatilidade condicional diária dos retornos logarítmicos do ativo $i$ estimada para a data $t$, calculada por alisamento exponencial, conforme a expressão:

$$
h_{i, t}=\sqrt{\lambda h_{i, t-1}^{2}+(1-\lambda) r_{i, t-1}^{2}}
$$

em que é o fator de decaimento exponencial, para o qual é utilizado o valor de 0,94, que corresponde ao valor adotado pelo RiskMetricsTM e tem sido amplamente utilizado na prática. ${ }^{17} \mathrm{O}$ VaR de um dia para a carteira de ativos é dado por:

$$
V a R_{t}^{1 d}=\sqrt{\sum_{i=1}^{n} \sum_{j=1}^{n} V a R_{i, t}^{1 d} \times V a R_{j, t}^{1 d} \rho_{(i, j), t}}
$$

em que a correlação entre os ativos $i$ e $j$ na data $t, \rho_{(i, j), t}$, é obtida por $\rho_{(i, j), t}=$ $\frac{h_{i, j}, t}{h_{i, t} h_{j, t}}$, tal que $h_{(i, j), t}$ denota a covariância condicional entre os ativos $i$ e $j$ na data $t$, obtida pela fórmula:

$$
h_{(i, j), t}=\lambda h_{(i, j), t-1}+(1-\lambda) r_{i, t-1} r_{j, t-1}
$$

Estendendo o horizonte para dez dias, o VaR da carteira será dado por:

$$
\operatorname{VaR}_{t}^{10 d}=\operatorname{Va} R_{t}^{1 d} \sqrt{10}
$$

\section{Modelo histórico híbrido}

Este modelo é uma abordagem que combina a metodologia histórica e o alisamento exponencial. O modelo tem como característica conferir maior peso às informações mais recentes da janela histórica de retornos da carteira. O peso é calculado por intermédio da seguinte fórmula:

\footnotetext{
${ }^{14}$ Metodologia desenvolvida pelo banco norte-americano J. P. Morgan.

${ }^{15}$ EWMA - Exponentially Weighted Moving Average.

${ }^{16} \mathrm{O}$ uso da função exponencial na fórmula permite a comparação direta entre as estimativas de VaR e os retornos efetivos, ao transformar a estimativa do quantil da série de retornos logarítmicos na correspondente estimativa do quantil da série de retornos efetivos.

${ }^{17}$ Ver Lemgruber e Ohanian (2001).
} 


$$
\text { Peso }=\left[\frac{(1-\lambda)}{\left(1-\lambda^{k}\right)}\right] \times \lambda^{n}
$$

onde $\lambda$ é o fator de alisamento, adotado como $0,97, k$ é o tamanho da janela histórica de retornos e $n$ é o número de ordem dos retornos, do mais recente ao último. ${ }^{18} \mathrm{O}$ retorno mais recente, por exemplo, tem $n=0$ e peso igual a 0,03 para uma janela de 252 dias úteis.

O VaR da carteira é calculado ordenando-se de maneira crescente os retornos e acumulando-se os pesos até que o somatório destes seja igual ao percentil de VaR desejado. O percentil de $1 \%$ para a posição comprada e de $99 \%$ para a vendida são obtidos por intermédio de interpolação linear entre os retornos adjacentes. ${ }^{19} \mathrm{O}$ VaR de dez dias é dado pelo produto do VaR de um dia pela raiz quadrada de dez.

\subsection{Aferição dos resultados}

A aferição é implementada para ambas as caudas das distribuições de retornos das carteiras. O período considerado no backtesting se estende de 2 de abril de 2001 a 25 de julho de 2003, num total de 572 observações. Vale observar que o Acordo da Basiléia não prevê o backtest para a exigência de capital, mas somente para o VaR de um dia dos modelos proprietários. Neste trabalho, contudo, busca-se também avaliar o desempenho da exigência de capital calculada por cada modelo.

O Comitê da Basiléia sugere um prazo (holding period) de dez dias, durante o qual as perdas poderiam hipoteticamente se acumular. A idéia subjacente é que, em períodos de crise, a instituição financeira precisaria de prazos mais dilatados para se desfazer de suas posições do que em uma situação normal. Desta forma, a comparação se dá entre os retornos acumulados por dez dias, para cada carteira avaliada, e a respectiva exigência de capital, sendo contabilizado o total de exceções ocorridas. Entende-se por exceção a ocorrência de uma perda superior à exigência de capital previamente fixada de acordo com o modelo. Neste caso, o fato de se considerar observações diárias de retornos de dez dias úteis pode gerar um aglomerado de exceções, na medida em que um retorno diário extremo tem seus efeitos estendidos pelos dez dias úteis subseqüentes. ${ }^{20}$

Então, para os modelos padronizados verifica-se simplesmente o número de vezes em que as perdas acumuladas em dez dias de uma dada carteira superam a exigência de capital no período de backtest. A aferição dos modelos baseados em VaR segue as diretrizes constantes de documento publicado pelo Comitê da Basiléia especificamente com este propósito. ${ }^{21}$ Assim, a cada três meses verifica-se a quantidade de vezes em que, nos últimos 250 dias úteis, o VaR diário é superado pela perda verificada no dia, para cada carteira. Basiléia estabelece três zonas

\footnotetext{
${ }^{18} \mathrm{O}$ valor de 0,97 para o $\lambda$ é baseado no artigo original do modelo Histórico Híbrido, The Best of Both Worlds, dos autores Boudoukh et alii (1998).

${ }^{19}$ Nos casos em que o primeiro peso apresenta percentual maior que $1 \%$, adota-se como critério a seleção do primeiro retorno.

${ }^{20} \mathrm{~A}$ cada dia são acumulados os retornos diários dos últimos 10 dias.

${ }^{21}$ Basel Committee on Banking Supervison (1996b).
} 
para o número de exceções ${ }^{22}$ observadas (em 250 observações) no backtest do VaR diário. Até quatro exceções, o modelo aferido se encontra na zona verde, ou seja, é aprovado. Um número de exceções entre cinco e nove situa o modelo na zona amarela, o que pode levar, caso não haja forte justificativa para o desvio, a um aumento do multiplicador, que pode chegar a $M=4$. Acima de nove exceções, o modelo entra na zona vermelha e a instituição avaliada pode ser intimada a adotar a abordagem padronizada. Além da metodologia indicada por Basiléia, observase também o número de vezes em que a perda acumulada em dez dias excede a exigência de capital considerando-se o total de 572 observações.

Adicionalmente, utiliza-se o teste de Kupiec, ${ }^{23}$ com nível de significância de $5 \%$, para o percentual de exceções do VaR diário. Testa-se a hipótese nula de que a proporção de exceções do modelo obtida empiricamente é igual ao nível pré-especificado (teórico) para o VaR.

Para uma avaliação de custo-benefício dos modelos, compara-se a exigência média de capital por carteira com os respectivos números de exceções ocorridas. Há um trade-off entre estes indicadores, uma vez que, para um dado modelo, uma maior exigência de capital tende a gerar um menor número de exceções. Neste caso, quão menores ambos os valores, mais eficiente é o modelo. Complementarmente, considera-se a diferença entre a exigência de capital e a respectiva perda $(E C-$ perda $)$ como forma a avaliar os aspectos conflitantes entre a proteção que um dado modelo proporciona e a sua eficiência na alocação de capital para a cobertura de risco. Por exemplo, dado que não tenham sido observadas exceções na $E C$, quanto maior a diferença entre a $E C$ e as perdas, maior a proteção, mas menor será a eficiência na alocação de capital. Também se considera a diferença entre a respectiva perda e a exigência de capital (perda $-E C$ ), pois, dado que tenha sido observada exceção de $E C$, avalia-se o quanto estas perdas ultrapassaram a $E C$ prevista por cada modelo.

\section{Resultados}

Para a comparação das metodologias, são apresentadas, para cada tipo de carteira, as exceções do VaR de um dia, avaliadas pelo teste de Kupiec, e as exceções de EC em relação aos retornos de dez dias. Além disso, são apresentados indicadores com o propósito de avaliar o quanto as perdas ultrapassaram a $E C$ (denominado $[$ Perdas $-E C]$ ) nas situações em que há exceção, bem como o quanto as perdas ficam aquém da EC (denominado $[E C-P e r d a s]$ ), caso contrário. ${ }^{24}$ São apenas mostradas figuras de backtesting das carteiras 1 e 3 , uma vez que as principais conclusões extraídas da interpretação destes podem ser estendidas às demais carteiras.

Uma observação interessante, comum a todos os modelos e carteiras, é o fato

\footnotetext{
${ }^{22}$ Neste artigo, o conceito de exceções se aplica tanto para $E C$ como para estimativa de VaR.

${ }^{23}$ Kupiec (1995).

${ }^{24}$ Os valores de $[$ Perdas $-E C]$ e $[E C-$ Perdas $]$ são apresentados como proporção do valor da carteira.
} 
de que as exceções ocorrem com maior freqüência na cauda direita (posição vendida) que na esquerda (ver, por exemplo, a Tabela A.3). Isto ocorre porque os retornos positivos da taxa de câmbio, no período estudado, atingiram patamares superiores, em módulo, aos dos retornos negativos (ver, por exemplo, a Figura A.5).

\subsection{Modelos de abordagem padronizada}

Dentre os modelos que seguem a abordagem padronizada, é possível observar que o modelo implementado pela regulamentação brasileira em sua versão anterior é bem mais conservador que o de Basiléia. A versão atual ameniza um pouco esta situação ao permitir, sob determinadas condições, a compensação em posições opostas de moedas diferentes. Todos estes modelos apresentam a característica comum de não responderem às alterações nos padrões de volatilidade, o que gera gráficos de comportamento de $E C$ ao longo do tempo com retas paralelas ao eixo das abscissas, uma vez que o montante das carteiras é mantido constante (figuras A.2 e A.3).

\section{Modelo padronizado de Basiléia}

Este é o único dentre os modelos de abordagem padronizada avaliados a apresentar exceções. As ocorrências mais relevantes dizem respeito às carteiras 1 e 6 , como mostra a Tabela A.3, que são constituídas apenas de um único ativo (posições em dólar norte-americano na carteira 1 e em yen na carteira 6). Para a cauda esquerda são registradas cinco exceções em ambas as carteiras, enquanto que para a cauda direita constata-se 28 exceções na carteira 1 e 33 na carteira 6. Para as demais carteiras, há poucas exceções e sempre na cauda direita das distribuições de retornos.

Pela Tabela A.2 é possível observar que a exposição cambial no modelo de Basiléia é sempre menor ou igual à exposição calculada pelo modelo da versão anterior e maior ou igual à exposição calculada pelo modelo da versão atual. A exigência de capital, contudo, é invariavelmente inferior para o modelo de Basiléia, em vista da menor alíquota utilizada. $\mathrm{O}$ fator de $8 \%$ sugerido pelo Comitê da Basiléia é possivelmente adequado a mercados pouco voláteis, como os dos paises do G-10. Para o Brasil, contudo, este percentual é claramente inadequado. Corrobora esta conclusão o fato de os modelos baseados em VaR fornecerem exigências de capital médias superiores, quando comparados à abordagem padronizada da $\mathrm{Ba}$ siléia (ver tabelas A.7, A.8 e A.9). ${ }^{25}$ Isto é explicado pela relação direta existente entre a volatilidade e o VaR, o que se reflete na exigência de capital.

\section{Modelo da resolução 2.606 de 27 de maio de 1999}

A exigência de capital determinada com base na versão anterior não apresenta exceções em qualquer das carteiras (ver observação da Tabela A.3). Isto se deve

\footnotetext{
${ }^{25}$ Em tese, espera-se que exatamente o oposto ocorra, como forma de motivar a adoção de modelos baseados em VaR pelas instituições financeiras, por serem estes mais sensíveis ao risco.
} 
em parte ao cálculo da exposição cambial, que considera a soma em módulo de todas as exposições líquidas em moedas estrangeiras e em ouro, sejam as posições compradas ou vendidas. Este valor só será idêntico ao calculado pelo modelo de Basiléia quando as posições líquidas forem todas compradas ou todas vendidas. Esta metodologia não oferece qualquer incentivo ao hedge cambial por meio de posições opostas em moedas fortemente correlacionadas.

Contudo, a principal causa da disparidade entre as exigências calculadas por este e pelo modelo de Basiléia é a alíquota a ser aplicada. O fator F" atualmente em uso é de 50\%, em comparação aos $8 \%$ de Basiléia. A Tabela A.2 mostra que, apesar de a exposição calculada ser a mesma para ambos os modelos nas carteiras 1,5 e 6 , a exigência de capital calculada pela versão anterior atingiu 50\% do valor total da carteira e mostrou-se 6,25 vezes maior que o requerimento de capital computado pelos parâmetros de Basiléia. Já nas carteiras 2 e 3, os efeitos acumulados da base de cálculo mais ampla e da maior alíquota aplicada tornam a exigência de capital mais que dez vezes superior àquela calculada pelo modelo padronizado de Basiléia. As figuras A.2 e A.3 permitem constatar a disparidade entre os requerimentos de capital determinados pelos diferentes modelos. Se por um lado não houve ocorrência de exceções para a atual legislação, por outro o capital exigido para fazer frente ao risco de mercado da taxa de câmbio foi bastante elevado.

Analogamente ao ocorrido com a versão anterior, a versão atual da norma brasileira não registra qualquer exceção. Em relação à versão anterior, podemos dizer que esta proposta caminha na direção da abordagem padronizada de Basiléia. Com efeito, a base de cálculo da Basiléia é idêntica à soma das parcelas $T_{1} \mathrm{e} T_{2}$, quando não há moedas fracas ou ouro. Neste caso, a base de cálculo da versão atual será menor que a de Basiléia, na medida em que T2 é multiplicada pelo fator de hedge que é menor que um. Ou seja, todas as posições que não foram alcançadas pela parcela $T_{1}$, entrarão na parcela $T_{2}$ com apenas $70 \%$ do valor. Logo, as moedas nobres com posições líquidas opostas terão um abatimento de $30 \%$ das posições compensadas, no cômputo da exposição. ${ }^{26}$ Deste modo, o que mantém a exigência bastante acima do modelo de Basiléia é o fator $F^{\prime \prime}$ que, a exemplo da versão anterior, foi definido em $50 \%$ contra os $8 \%$ de Basiléia. As figuras A.2 e A.3 confirmam que a diferença entre o requerimento de capital deste e do modelo de Basiléia ainda é considerável. Contudo, é possível observar nas carteiras 2, 3, 4 e 5 o efeito do incentivo à adoção de posições opostas em moedas fortes e ouro (Tabela A.2). Nestes casos, a exigência de capital foi aproximadamente a metade do que seria requerido pela versão anterior.

\subsection{Modelos baseados em VaR}

Os modelos baseados em VaR apresentam EC's médias consideravelmente menores que ambas as versões do modelo da Resolução 2.606 e maiores que o de

\footnotetext{
${ }^{26}$ Quando ouro ou moedas se encontram na mesma posição, a diversificação não é considerada pelo modelo, mesmo se tratando de moedas fortes.
} 
Basiléia. Porém, com multiplicador igual a 3, há situações em que requerem uma alocação de capital maior do que o modelo da norma vigente (Figura A.5). ${ }^{27}$ A menor diferença entre os requerimentos médios de capital destes modelos (baseados em VaR versus norma atual) ocorre para as carteiras compostas por um único ativo (Tabelas A.7, A.8 e A.9).

\section{Modelo histórico}

São consideradas duas versões do modelo Histórico, com janela única e com janela dupla.

Pelo teste de Kupiec, os resultados do VaR são melhores para o modelo histórico com janela dupla, que não é rejeitado, para a posição comprada, para nenhuma carteira (Tabela A.6). O modelo histórico com uma janela não é rejeitado apenas para a carteira $2 \mathrm{em}$ ambas as caudas.

Em relação aos sete sub-períodos analisados (teste de Basiléia), os resultados não são satisfatórios (Tabelas A.4 e A.5). O modelo histórico com uma janela é o único modelo baseado em VaR que apresenta ocorrências (uma exceção para cada uma das carteiras 1, 3 e 6) na zona vermelha. O modelo histórico com janela dupla apresenta proporções aproximadamente iguais de ocorrências nas zonas verde e amarela.

Em relação à $E C$ calculada com $M=2$, o modelo histórico com janela dupla apresenta o menor número de exceções dentre os modelos baseados em VaR (cinco, todas na cauda direita). O modelo histórico com uma janela é o que apresenta maior número total de exceções (nove, todas também na cauda direita) dentre os baseados em VaR (Tabela A.3). Porém, quando se avalia $[$ perda-EC], verificase que estas medidas não são, de uma forma geral, de magnitude reduzida (Tabela A.10).

Ao se utilizar $M=3$, houve apenas uma exceção na carteira 3 em ambas as versões, para a cauda direita (ver observação da Tabela A.3). Porém, o valor de $[$ perda $-E C]$ é irrelevante (ver observação da Tabela A.10).

Uma questão interessante diz respeito à avaliação, pela instituição supervisora, dos desempenhos dos modelos internos considerados inadequados pelos padrões da Basiléia, ou seja, com número de exceções do VaR diário superior a quatro em um período de 250 dias. Nos moldes do Acordo, ocorrências na zona amarela levam usualmente a um aumento do multiplicador, enquanto ocorrências na zona vermelha podem determinar a revisão do modelo de VaR utilizado. Acreditamos que em mercados emergentes tal avaliação deva ser extremamente criteriosa uma vez que o VaR é reconhecidamente uma boa medida de risco para situações normais, mas é bastante questionado em situações que apresentem fortes variações do padrão de volatilidade, o que ocorre com certa frequiência em mercados como o

\footnotetext{
${ }^{27}$ Vale lembrar que se considera o fator $F^{\prime \prime}$ igual a 0,5, no modelo da Resolução 2.606, para todo o período estudado. Entretanto, o Banco Central do Brasil aumentou o fator para 0,75 em 7 de outubro de 2002 e, em seguida, elevou ainda mais o fator para 1 em 11 de outubro de 2002. Somente em 2 de julho de 2003, o fator voltou a cair para 0,5. Ver Banco Central do Brasil (2002a,b, 2003b), respectivamente.
} 
brasileiro. O período estudado neste trabalho, conforme sublinhado anteriormente, inclui, pelo menos, três episódios que se encaixam neste perfil: a crise energética, a crise da Argentina e a sucessão presidencial.

\section{Modelo baseado em alisamento exponencial}

Em relação às estimativas de VaR, como pode ser observado na Tabela A.6, o Modelo Baseado em Alisamento Exponencial, a exemplo do modelo histórico de duas janelas, não é rejeitado para nenhuma carteira para a cauda esquerda pelo teste de Kupiec. Já para a cauda direita, o modelo só não é rejeitado para a carteira 3 em que o limite máximo de exceções é obtido (dez exceções). As carteiras que obtiveram o maior número de exceções (catorze) foram as carteiras compostas por uma única moeda (carteiras 1 e 6).

Quanto aos sub-períodos (teste de Basiléia), o modelo apresenta, de um modo geral, melhores resultados que os outros modelos, com mais sub-períodos na zona verde. Não há ocorrências na zona vermelha (Tabelas A.4 e A.5). Vale aqui a mesma observação feita na seção anterior com respeito à avaliação dos modelos com base no backtest do VaR de um dia em mercados sujeitos a fortes flutuações da volatilidade.

Quanto à EC, o modelo de VAR-COV com alisamento exponencial possui menor média de exigência de capital que os outros que seguem a abordagem interna, como pode ser observado nas Tabelas A.8 e A.9.

Para o multiplicador 3, o modelo não apresenta exceções de $E C$ para nenhuma carteira em ambas as caudas (ver observação da Tabela A.3). Para o multiplicador 2, há um total de nove exceções de $E C$, todas para a posição vendida, o que mostra um desempenho inferior aos modelos histórico com janela dupla e histórico híbrido (Tabela A.3). Porém, pela Tabela A.10, observa-se que o valor médio e o valor máximo de $[$ perdas - EC] não são elevados. Pelas Tabelas A.11 e A.12, pode-se notar que este modelo apresenta, dentre os baseados em VaR, a menor média de $[E C-$ perdas $]$ e muitas vezes um dos maiores valores mínimos desta medida, o que significa uma proteção maior sem excesso de alocação de capital para cobrir o risco de mercado.

Pode-se observar pela figura A.4 que a série de EC calculada pelo modelo de VAR-COV evidencia um acompanhamento mais próximo das alterações dos padrões de volatilidade dos retornos que ambas as versões do modelo histórico

\section{Modelo histórico híbrido}

Em relação aos resultados do $\mathrm{VaR}$, o modelo histórico híbrido só não apresenta pior desempenho, segundo o teste de Kupiec, que o modelo histórico com uma janela (Tabela A.6).

Contudo, quanto ao teste de Basiléia (Tabelas A.4 e A.5), o modelo não apresenta qualquer sub-período com valor de exceções superior a sete. Porém, apresenta menos sub-períodos dentro da zona verde que os modelos de VAR-COV com alisamento exponencial e Histórico com janela dupla. 
Em relação ao backtesting de $E C$ para o multiplicador 2, o modelo apresenta um total de seis exceções de $E C$, todas na cauda direita (Tabela A.3). Os valores de $[$ Perda $-E C]$ máximos (Tabela A.10), nestes casos, são menores que no modelo de alisamento exponencial. A média de $E C$ (Tabela A.8) e de [EC-perda] com multiplicador 2 (Tabelas A.11 e A.12), é próxima à média do modelo histórico com uma janela e maior que a do alisamento exponencial. Para o multiplicador 3 , o backtesting não apresenta exceções de $E C$. A exemplo do que ocorre com o modelo de alisamento exponencial, o perfil da série de $E C$ calculada pelo modelo histórico híbrido responde mais rapidamente às flutuações da volatilidade, em comparação a ambas as versões do modelo histórico (figura A.4).

\section{Conclusões e Considerações Finais}

Este artigo avalia modelos de determinação da exigência de capital para cobertura de risco de mercado decorrente da exposição em posições sujeitos à variação cambial, exceto opções. Os modelos examinados foram agrupados segundo a abordagem padronizada ou de modelos proprietários (baseados em VaR). O primeiro grupo abrange o modelo padronizado de Basiléia e o adotado pela legislação brasileira, nas versões anterior e posterior à alteração implementada pela Circular 3.217, de 19 de dezembro de 2003, posteriormente substituída pela Circular 3.229, de 25 de março de 2004. No segundo grupo estão o modelo histórico, com uma e duas janelas, o modelo de VAR-COV com alisamento exponencial e o modelo histórico híbrido.

Para as carteiras analisadas, o modelo padronizado adotado pela atual legislação, em ambas as versões, possui uma exigência de capital média total consideravelmente maior do que a dos modelos baseados em VaR com multiplicador igual a 3. Porém, há momentos em que requer uma alocação de capital menor. Isto sugere que, mesmo em patamares fortemente conservadores, um modelo de abordagem padronizada pode não prover proteção adequada contra perdas inesperadas em momentos de pico da volatilidade. Em sua versão atual, mesmo ao considerar parcialmente a correlação entre as principais moedas e também o ouro, o modelo se comporta exatamente como na versão anterior nos casos em que a carteira é constituída por um único ativo, por ativos diferentes na mesma posição ou por moedas fracas. Contudo, apresenta um avanço em relação à versão anterior ao permitir alguma compensação entre determinados ativos em posições opostas.

Como esperado, os modelos baseados em VaR apresentam menores alocações de capital que os modelos padronizados, à exceção do modelo padronizado de Basiléia que apresenta um grande número de exceções, evidenciando uma inadequação à alta volatilidade do mercado de câmbio do Brasil.

A utilização de uma janela na metodologia histórica apresenta resultados inferiores aos demais modelos baseados em VaR. Os outros modelos, histórico com duas janelas, alisamento exponencial, e histórico híbrido apresentam resultados semelhantes. Pelo teste de Basiléia, o modelo de VAR-COV com alisamento exponencial obteve o melhor desempenho, assim como para a exigência de capital 
com multiplicador 3, uma vez que conjuga uma menor média com menor número de exceções. Contudo, para o multiplicador 2, este modelo é o que apresenta mais exceções de $E C$. Neste caso, o melhor desempenho é do histórico com duas janelas. Vale observar que a EC para os modelos histórico híbrido e de VAR-COV com alisamento exponencial acompanham com maior proximidade o comportamento dos retornos em relação aos outros modelos. Além disso, é importante ressaltar que os valores pelos quais as perdas excederam a respectiva exigência de capital não foram elevados.

O período de estudo compreendeu momentos de forte volatilidade no mercado brasileiro de câmbio. Desta forma, parte das exceções exibidas pelo VaR de um dia em todos os modelos ocorre devido a este fato. O Comitê de Basiléia prevê o aumento do multiplicador ou a revisão dos modelos internos que não atendam ao desempenho mínimo previsto. Em se tratando de mercados emergentes, sujeitos a fortes e freqüentes oscilações dos padrões de volatilidade, é importante avaliar criteriosamente as circunstâncias em que o fraco desempenho ocorre, buscando detectar se o modelo realmente apresenta inconsistências, ou se apenas reflete condições de mercado fortemente adversas.

\section{Referências}

Banco Central do Brasil (1999a). Circular no. 2.894. http://www.bcb.gov.br.

Banco Central do Brasil (1999b). Resolução no. 2.606. http://www.bcb.gov.br.

Banco Central do Brasil (2000). Circular no. 2.972. http://www.bcb.gov.br.

Banco Central do Brasil (2002a). Circular no. 3.155. http://www.bcb.gov.br.

Banco Central do Brasil (2002b). Circular no. 3.156. http://www.bcb.gov.br.

Banco Central do Brasil (2003a). Circular no. 3.194. http://www.bcb.gov.br.

Banco Central do Brasil (2003b). Circular no. 3.217. http://www.bcb.gov.br.

Banco Central do Brasil (2004). Circular no. 3.229. http://www.bcb.gov.br.

Basel Committee on Banking Supervison (1996a). Amendment to the capital accord to incorporate market risks. http://www.bis.org.

Basel Committee on Banking Supervison (1996b). Supervisory framework for the use of "backtesting" in conjunction with the internal models aproach to market risk capital requirements. http://www.bis.org.

Boudoukh, J., Richardson, M., \& Whitelaw, R. (1998). The best of both worlds. Risk, 11:64-67.

Jorion, P. (2000). Value at Risk: The New Benchmark for Managing Financial Risk. McGraw-Hill Trade, $2^{\text {nd }}$ edition. 
Kupiec, P. (1995). Techniques for verifying the accuracy of risk measurement models. Journal of Derivatives, 2:73-84.

Lemgruber, E. F. \& Ohanian, G. (2001). O modelo de projeção de volatilidade do RiskMetrics e a hipótese de distribuição normal condicional para alguns fatores de risco do Brasil. In Lemgruber, E. F. e. a., editor, Gestão de Risco e Derivativos: Aplicações No Brasil, pages 112-124. Editora Atlas, São Paulo.

Riskmetrics Group (1996). RiskMetrics - Technical Document. J. P. Morgan, New York. http://www.riskmetrics.com. 


\section{Anexo}

Tabela A.1

Participação percentual das moedas em cada carteira

\begin{tabular}{l|rrrrrr}
\hline \multirow{2}{*}{ Moedas } & \multicolumn{7}{|c}{ Carteiras } \\
\cline { 2 - 7 } & 1 & 2 & 3 & 4 & 5 & 6 \\
\hline Dólar & 100,00 & 300,00 & 264,98 & 0,00 & 75,00 & 0,00 \\
Euro & 0,00 & $-200,00$ & $-47,18$ & 200,00 & 75,00 & 0,00 \\
Libra & 0,00 & 0,00 & $-3,37$ & 0,00 & 0,00 & 0,00 \\
Iene & 0,00 & 0,00 & $-113,7$ & 0,00 & 0,00 & 100,00 \\
Franco & 0,00 & 0,00 & $-0,75$ & $-50,00$ & 0,00 & 0,00 \\
Ouro & 0,00 & 0,00 & 0,00 & $-50,00$ & $-50,00$ & 0,00 \\
\hline
\end{tabular}

Obs.: Todas as carteiras têm valor líquido de $\$ 100$ unidades

monetárias.

Tabela A.2

Exposição e exigência de capital - modelos de abordagem padronizada

\begin{tabular}{|c|c|c|c|c|c|c|}
\hline \multirow[b]{2}{*}{ Modelos } & \multicolumn{3}{|c|}{ Carteira 1} & \multicolumn{3}{|c|}{ Carteira 2} \\
\hline & Exposição & $E C$ & $E C / E C$ de Basiléia & Exposição & $E C$ & $E C / E C$ de Basiléia \\
\hline Basiléia & 100,00 & 8,00 & 1,00 & 300,00 & 24,00 & 1,00 \\
\hline Versão Anterior & 100,00 & 50,00 & 6,25 & 500,00 & 250,00 & 10,42 \\
\hline Versão Atual & 100,00 & 50,00 & 6,25 & 240,00 & 120,00 & 5,00 \\
\hline & \multicolumn{3}{|c|}{ Carteira 3} & \multicolumn{3}{|c|}{ Carteira 4} \\
\hline Modelos & \begin{tabular}{|l|} 
Exposição \\
\end{tabular} & $E C$ & $E C / E C$ de Basiléia & Exposição & $E C$ & $E C / E C$ de Basiléia \\
\hline Basiléia & 264,98 & 21,2 & 1,00 & 250,00 & 20,00 & 1,00 \\
\hline Versão Anterior & 429,96 & 214,98 & 10,14 & 300,00 & 150,00 & 7,50 \\
\hline Versão Atual & 215,49 & 107,74 & 5,08 & 170,00 & 85,00 & 4,25 \\
\hline \multirow[b]{2}{*}{ Modelos } & \multicolumn{3}{|c|}{ Carteira 5} & \multicolumn{3}{|c|}{ Carteira 6} \\
\hline & Exposição & $E C$ & $E C / E C$ de Basiléia & Exposição & $E C$ & $E C / E C$ de Basiléia \\
\hline Basiléia & 200,00 & 16,00 & 1,00 & 100,00 & 8,00 & 1,00 \\
\hline Versão Anterior & 200,00 & 100,00 & 6,25 & 100,00 & 50,00 & 6,25 \\
\hline Versão Atual & 135,00 & 67,50 & 4,22 & 100,00 & 50,00 & 6,25 \\
\hline
\end{tabular}

Obs.: A exposição e a exigência de capital $(E C)$ se referem a carteiras de $\$ 100$ unidades monetárias. 
Tabela A.3

Exceções da exigência de capital para os modelos de abordagem padronizada e modelos baseados em VaR com multiplicador 2

\begin{tabular}{|c|c|c|c|c|c|c|}
\hline \multirow[b]{2}{*}{ Métodos } & \multicolumn{2}{|c|}{ Carteira 1} & \multicolumn{2}{|c|}{ Carteira 2} & \multicolumn{2}{|c|}{ Carteira 3} \\
\hline & \begin{tabular}{|l} 
Cauda Esq. \\
.
\end{tabular} & Cauda Dir. & Cauda Esq. & . Cauda Dir. & Cauda Esq. & Cauda Dir \\
\hline Basiléia & 5 & 28 & 0 & 1 & 0 & 4 \\
\hline Histórico - 1 Janela & 0 & 5 & 0 & 1 & 0 & 3 \\
\hline Histórico - 2 Janelas & 0 & 1 & 0 & 1 & 0 & 3 \\
\hline VAR-COV com & & & & & & \\
\hline Alisam. Exponencial & 0 & 3 & 0 & 3 & 0 & 3 \\
\hline Histórico Híbrido & 0 & 2 & 0 & 1 & 0 & 3 \\
\hline \multirow[b]{2}{*}{ Métodos } & \multicolumn{2}{|c|}{ Carteira 4} & \multicolumn{2}{|c|}{ Carteira 5} & \multicolumn{2}{|c|}{ Carteira 6} \\
\hline & Cauda Esq. & Cauda Dir. & Cauda Esq. & . Cauda Dir. & Cauda Esq. & Cauda Dir \\
\hline Basiléia & 0 & 3 & 0 & 7 & 5 & 33 \\
\hline Histórico - 1 Janela & 0 & 0 & 0 & 0 & 0 & 0 \\
\hline $\begin{array}{l}\text { Histórico - } 2 \text { Janelas } \\
\text { VAR-COV com }\end{array}$ & 0 & 0 & 0 & 0 & 0 & 0 \\
\hline Alisam. Exponencial & 0 & 0 & 0 & 0 & 0 & 0 \\
\hline Histórico Híbrido & 0 & 0 & 0 & 0 & 0 & 0 \\
\hline
\end{tabular}


Tabela A.4

Backtest do VaR de 1 Dia - Teste de Basiléi

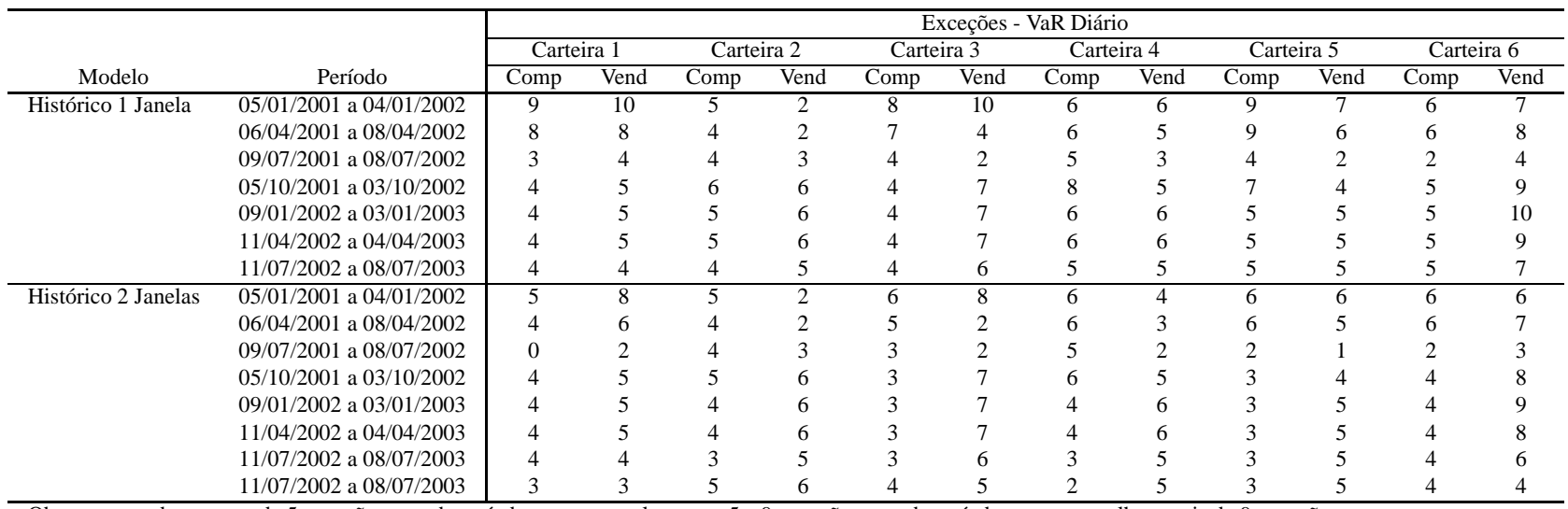

Obs: zona verde - menos de 5 exceções no sub-período; zona amarela - entre 5 e 9 exceções no sub-período; zona vermelha - mais de 9 exceções. 
Tabela A.5

Backtest do VaR de 1 dia - teste de Basiléia (continuação)

\begin{tabular}{|c|c|c|c|c|c|c|c|c|c|c|c|c|c|}
\hline \multirow[b]{3}{*}{ Modelo } & \multirow[b]{3}{*}{ Período } & \multicolumn{12}{|c|}{ Exceções - VaR Diário } \\
\hline & & \multicolumn{2}{|c|}{ Carteira 1} & \multicolumn{2}{|c|}{ Carteira 2} & \multicolumn{2}{|c|}{ Carteira 3} & \multicolumn{2}{|c|}{ Carteira 4} & \multicolumn{2}{|c|}{ Carteira 5} & \multicolumn{2}{|c|}{ Carteira 6} \\
\hline & & Comp & Vend & Comp & Vend & Comp & Vend & Comp & Vend & Comp & Vend & Comp & Vend \\
\hline VAR-COV com & $05 / 01 / 2001$ a $04 / 01 / 2002$ & 5 & 9 & 2 & 3 & 3 & 3 & 1 & 5 & 1 & 4 & 3 & 5 \\
\hline \multirow{6}{*}{ Alisam. Exponencial } & $06 / 04 / 2001$ a $08 / 04 / 2002$ & 5 & 5 & 3 & 3 & 5 & 2 & 1 & 4 & 1 & 3 & 3 & 6 \\
\hline & 09/07/2001 a $08 / 07 / 2002$ & 3 & 3 & 4 & 6 & 5 & 3 & 2 & 3 & 1 & 2 & 1 & 6 \\
\hline & $05 / 10 / 2001$ a $03 / 10 / 2002$ & 4 & 5 & 4 & 8 & 5 & 5 & 2 & 3 & 1 & 3 & 2 & 8 \\
\hline & 09/01/2002 a 03/01/2003 & 2 & 5 & 3 & 7 & 4 & 5 & 2 & 3 & 1 & 4 & 2 & 8 \\
\hline & $11 / 04 / 2002$ a $04 / 04 / 2003$ & 2 & 5 & 4 & 8 & 4 & 6 & 2 & 4 & 2 & 4 & 4 & 7 \\
\hline & $11 / 07 / 2002$ a $08 / 07 / 2003$ & 3 & 3 & 5 & 6 & 4 & 5 & 2 & 5 & 3 & 5 & 4 & 4 \\
\hline \multirow[t]{7}{*}{ Histórico Híbrido } & $05 / 01 / 2001$ a $04 / 01 / 2002$ & 5 & 6 & 6 & 5 & 5 & 4 & 4 & 5 & 5 & 6 & 6 & 6 \\
\hline & $06 / 04 / 2001$ a $08 / 04 / 2002$ & 4 & 3 & 3 & 4 & 4 & 3 & 3 & 5 & 5 & 1 & 1 & 6 \\
\hline & 09/07/2001 a $08 / 07 / 2002$ & 2 & 2 & 2 & 5 & 5 & 5 & 5 & 6 & 6 & 4 & 4 & 4 \\
\hline & $05 / 10 / 2001$ a $03 / 10 / 2002$ & 4 & 4 & 4 & 5 & 5 & 7 & 7 & 6 & 6 & 6 & 6 & 3 \\
\hline & 09/01/2002 a 03/01/2003 & 3 & 4 & 4 & 4 & 4 & 6 & 6 & 6 & 6 & 6 & 6 & 2 \\
\hline & $11 / 04 / 2002$ a $04 / 04 / 2003$ & 3 & 4 & 4 & 5 & 5 & 7 & 7 & 4 & 4 & 6 & 6 & 2 \\
\hline & $11 / 07 / 2002$ a 08/07/2003 & 2 & 3 & 3 & 6 & 6 & 7 & 7 & 4 & 4 & 5 & 5 & 2 \\
\hline
\end{tabular}


Tabela A.6

Backtest do VaR de 1 dia - teste de Kupiec

\begin{tabular}{|c|c|c|c|c|c|c|}
\hline \multirow[b]{2}{*}{ Métodos } & \multicolumn{2}{|c|}{ Carteira 1} & \multicolumn{2}{|c|}{ Carteira 2} & \multicolumn{2}{|c|}{ Carteira 3} \\
\hline & Cauda Esq. & Cauda Dir. & Cauda Esq. & Cauda Dir. & Cauda Esq. & Cauda Dir. \\
\hline Histórico - 1 Janela & 13 & 15 & 10 & 8 & 12 & 17 \\
\hline Histórico - 2 Janela & 9 & 13 & 9 & 8 & 9 & 15 \\
\hline VAR-COV com & 9 & 14 & 9 & 12 & 10 & 10 \\
\hline Alisam. Exponencial & & & & & & \\
\hline Histórico Híbrido & 8 & 11 & 13 & 13 & 13 & 14 \\
\hline \multirow[b]{2}{*}{ Métodos } & \multicolumn{2}{|c|}{ Carteira 4} & \multicolumn{2}{|c|}{ Carteira 5} & \multicolumn{2}{|c|}{ Carteira 6} \\
\hline & $\begin{array}{l}\text { Cauda Esq. } \\
\text { Ca }\end{array}$ & Cauda Dir. & Cauda Esq. & Cauda Dir. & Cauda Esq. & Cauda Dir. \\
\hline Histórico - 1 Janela & 12 & 12 & 14 & 12 & 14 & 12 \\
\hline Histórico - 2 Janela & 10 & 10 & 9 & 11 & 10 & 15 \\
\hline VAR-COV com & 4 & 11 & 4 & 11 & 7 & 14 \\
\hline Alisam. Exponencial & & & & & & \\
\hline Histórico Híbrido & 9 & 12 & 9 & 9 & 7 & 10 \\
\hline
\end{tabular}

\begin{tabular}{l|cccccc} 
Histórico Híbrido & 9 & $\mathbf{1 2}$ & 9 & 9 & 7 & 10 \\
\hline Obs: O intervalo de não rejeição do teste está entre duas e dez exceções. & Em vermelho estão os
\end{tabular} modelos rejeitados.

Tabela A.7

Exigência de capital média - modelos de abordagem padronizada

\begin{tabular}{cc|cccccc}
\hline \multirow{2}{*}{ Modelos } & & \multicolumn{7}{c}{ Carteiras } \\
\cline { 3 - 8 } & & 1 & 2 & 3 & 4 & 5 & 6 \\
\hline Padrão Basiléia & Comp. & 8,00 & 24,00 & 21,20 & 20,00 & 16,00 & 8,00 \\
& Vend. & 8,00 & 24,00 & 21,20 & 20,00 & 16,00 & 8,00 \\
\multirow{3}{*}{ Versão Anterior } & Comp. & 50,00 & 250 & 214,98 & 150,00 & 100,00 & 50,00 \\
& Vend. & 50,00 & 250,00 & 214,98 & 150,00 & 100,00 & 50,00 \\
& Comp. & 50,00 & 120,00 & 107,74 & 85,00 & 67,50 & 50,00 \\
& Vend. & 50,00 & 120,00 & 107,74 & 85,00 & 67,50 & 50,00 \\
\hline
\end{tabular}

Tabela A.8

Exigência de capital média - modelos baseados em VaR - multiplicador 2

\begin{tabular}{lc|cccccc}
\hline \multicolumn{2}{c|}{} & \multicolumn{6}{|c}{ Carteiras } \\
\cline { 3 - 8 } Modelos & & 1 & 2 & 3 & 4 & 5 & 6 \\
\hline Histórico & Comp. & 18,57 & 25,5 & 21,57 & 28,33 & 26,12 & 26,12 \\
1 Janela & Vend. & 18,58 & 28,74 & 21,79 & 32,27 & 28,4 & 28,4 \\
Histórico & Comp. & 20,69 & 27,21 & 22,95 & 30,25 & 28,2 & 23,41 \\
2 Janelas & Vend. & 19,37 & 29,88 & 23,47 & 33,99 & 30,65 & 22,8 \\
VAR-COV cl & Comp. & 17,3 & 25,06 & 21,3 & 27,78 & 25 & 19,91 \\
Alis. Exp. & Vend. & 17,92 & 25,93 & 22 & 28,88 & 25,97 & 20,68 \\
Histórico & Comp. & 20,55 & 28,28 & 24,57 & 29,83 & 28,49 & 22,82 \\
Híbrido & Vend. & 17,76 & 27,42 & 21,35 & 32,18 & 28,68 & 21,41 \\
\hline
\end{tabular}


Tabela A.9

Exigência de capital média - modelos baseados em VaR - multiplicador 3

\begin{tabular}{lc|cccccc}
\hline & & \multicolumn{5}{|c}{ Carteiras } \\
\cline { 3 - 7 } \multicolumn{1}{c}{ Modelos } & & 1 & 2 & 3 & 4 & 5 & 6 \\
\hline Histórico 1 Janela & Comp. & 27,85 & 38,25 & 32,35 & 42,49 & 39,18 & 39,18 \\
\multirow{3}{*}{ Histórico 2 Janelas } & Vend. & 27,87 & 43,11 & 32,69 & 48,41 & 42,60 & 42,60 \\
\multirow{3}{*}{ VAR-COV com Alisam. Exponencial } & Comp. & 31,04 & 40,81 & 34,43 & 45,38 & 42,3 & 35,11 \\
\multirow{3}{*}{ Histórico Híbrido } & Vend. & 29,05 & 44,83 & 35,20 & 50,98 & 45,97 & 34,20 \\
& Comp. & 25,81 & 37,54 & 31,87 & 41,63 & 37,38 & 29,80 \\
& Vend. & 26,71 & 38,81 & 32,88 & 43,25 & 38,79 & 30,93 \\
& Comp. & 30,46 & 42,24 & 36,64 & 44,39 & 42,32 & 33,87 \\
& Vend. & 26,64 & 41,13 & 32,03 & 48,27 & 43,02 & 32,11 \\
\hline
\end{tabular}

Tabela A.10

Diferença entre as perdas que excederam a exigência de capital e a exigência de capital - posição vendida multiplicador 2 - em percentual do valor da carteira

\begin{tabular}{lc|cccccc}
\hline \multirow{2}{*}{ Modelos } & & \multicolumn{5}{|c}{ Carteiras } \\
\cline { 3 - 7 } & & 1 & 2 & 3 & 4 & 5 & 6 \\
\hline \multirow{2}{*}{ Basiléia } & Méd. & $4,54 \%$ & $1,95 \%$ & $1,88 \%$ & $5,07 \%$ & $5,15 \%$ & $3,72 \%$ \\
& Máx. & $14,33 \%$ & $1,95 \%$ & $3,54 \%$ & $9,26 \%$ & $11,97 \%$ & $14,78 \%$ \\
\multirow{3}{*}{ Histórico 1 Janela 2 Janelas } & Méd. & $0,96 \%$ & $2,65 \%$ & $5,29 \%$ & $0,00 \%$ & $0,00 \%$ & $0,00 \%$ \\
& Máx. & $2,85 \%$ & $2,65 \%$ & $8,29 \%$ & $0,00 \%$ & $0,00 \%$ & $0,00 \%$ \\
\multirow{2}{*}{ VAR-COV com Alisam. Exponencial } & Méd. & $2,85 \%$ & $2,65 \%$ & $5,29 \%$ & $0,00 \%$ & $0,00 \%$ & $0,00 \%$ \\
& Mád. & $2,85 \%$ & $2,65 \%$ & $8,29 \%$ & $0,00 \%$ & $0,00 \%$ & $0,00 \%$ \\
\multirow{2}{*}{ Histórico Híbrido } & Máx. & $5,81 \%$ & $2,37 \%$ & $4,38 \%$ & $0,00 \%$ & $0,00 \%$ & $0,00 \%$ \\
& Méd. & $2,74 \%$ & $3,41 \%$ & $3,91 \%$ & $0,00 \%$ & $0,00 \%$ & $0,00 \%$ \\
& Máx. & $4,56 \%$ & $3,41 \%$ & $6,92 \%$ & $0,00 \%$ & $0,00 \%$ & $0,00 \%$ \\
\hline
\end{tabular}

Obs.1: Os modelos padronizados relativos à Versão Anterior e à Versão Atual não apresentam exceções de EC para qualquer carteira.

Obs.2: Com relação aos modelos de $\mathrm{EC}$ baseados em VaR com $\mathrm{M}=3$, há uma única exceção de

EC para o modelo histórico, em ambas as versões, para a cauda direita na carteira 3, com uma

diferença percentual de $0,07 \%$ entre a perda e a EC. 
Tabela A.11

Diferença entre a exigência de capital e as perdas que não excederam a exigência de capital - posição comprada multiplicadores 2 e 3 - em percentual do valor da carteira

\begin{tabular}{|c|c|c|c|c|c|c|c|c|}
\hline \multirow{2}{*}{\multicolumn{3}{|c|}{ Modelos }} & \multicolumn{6}{|c|}{ Carteiras } \\
\hline & & & 1 & 2 & 3 & 4 & 5 & 6 \\
\hline \multirow[t]{6}{*}{ Padronizados } & Basiléia & Méd. & $4,95 \%$ & $19,39 \%$ & $17,25 \%$ & $16,67 \%$ & $12,92 \%$ & $4,72 \%$ \\
\hline & & Mín. & $0,01 \%$ & $8,05 \%$ & $7,49 \%$ & $7,60 \%$ & $5,36 \%$ & $0,05 \%$ \\
\hline & Versão Anterior & Méd. & $46,83 \%$ & $245,39 \%$ & $211,03 \%$ & $146,67 \%$ & $96,92 \%$ & $46,62 \%$ \\
\hline & & Mín. & $40,07 \%$ & $234,05 \%$ & $201,27 \%$ & $137,60 \%$ & $89,36 \%$ & $41,38 \%$ \\
\hline & Versão Atual & Méd. & $46,83 \%$ & $115,39 \%$ & $103,80 \%$ & $81,67 \%$ & $64,42 \%$ & $46,62 \%$ \\
\hline & & Mín. & $40,07 \%$ & $104,05 \%$ & $94,04 \%$ & $72,60 \%$ & $56,86 \%$ & $41,38 \%$ \\
\hline \multirow{8}{*}{$\begin{array}{l}\text { Baseados em VaR } \\
\text { Multiplicador } 2\end{array}$} & Histórico 1 Janela & Méd. & $17,60 \%$ & $21,29 \%$ & $18,29 \%$ & $26,23 \%$ & $24,36 \%$ & $24,36 \%$ \\
\hline & & Mín. & $3,26 \%$ & $12,70 \%$ & $4,13 \%$ & $9,67 \%$ & $8,48 \%$ & $8,48 \%$ \\
\hline & Histórico 2 Janelas & Méd. & $19,97 \%$ & $23,05 \%$ & $19,76 \%$ & $28,32 \%$ & $26,77 \%$ & $21,95 \%$ \\
\hline & & Mín. & $4,11 \%$ & $12,73 \%$ & $5,28 \%$ & $10,93 \%$ & $9,28 \%$ & $6,54 \%$ \\
\hline & VAR-COV c/ Alis. Exp. & Méd. & $15,00 \%$ & $19,88 \%$ & $17,11 \%$ & $24,62 \%$ & $22,17 \%$ & $17,33 \%$ \\
\hline & & Mín. & $6,34 \%$ & $5,64 \%$ & $5,91 \%$ & $15,54 \%$ & $11,50 \%$ & $8,89 \%$ \\
\hline & Histórico Híbrido & Méd. & $19,01 \%$ & $23,61 \%$ & $20,79 \%$ & $27,09 \%$ & $26,63 \%$ & $21,09 \%$ \\
\hline & & Mín. & $5,23 \%$ & $7,99 \%$ & $7,07 \%$ & $12,14 \%$ & $9,25 \%$ & $6,14 \%$ \\
\hline \multirow{8}{*}{$\begin{array}{l}\text { Baseados em VaR } \\
\text { Multiplicador } 3\end{array}$} & Histórico 1 Janela & Méd. & $27,98 \%$ & $34,23 \%$ & $29,42 \%$ & $41,00 \%$ & $38,06 \%$ & $38,06 \%$ \\
\hline & & Mín. & $7,61 \%$ & $24,51 \%$ & $10,10 \%$ & $20,70 \%$ & $16,44 \%$ & $16,44 \%$ \\
\hline & Histórico 2 Janelas & Méd. & $31,54 \%$ & $36,87 \%$ & $31,61 \%$ & $44,13 \%$ & $41,68 \%$ & $34,62 \%$ \\
\hline & & Mín. & $8,89 \%$ & $24,56 \%$ & $11,82 \%$ & $22,60 \%$ & $17,03 \%$ & $13,23 \%$ \\
\hline & VAR-COV c/ Alis. Exp. & Méd. & $23,96 \%$ & $32,07 \%$ & $27,58 \%$ & $38,57 \%$ & $34,65 \%$ & $27,63 \%$ \\
\hline & & Mín. & $10,42 \%$ & $16,44 \%$ & $13,59 \%$ & $25,77 \%$ & $19,01 \%$ & $16,67 \%$ \\
\hline & Histórico Híbrido & Méd. & $29,73 \%$ & $37,52 \%$ & $32,92 \%$ & $42,10 \%$ & $41,09 \%$ & $32,96 \%$ \\
\hline & & Mín. & $10,99 \%$ & $16,16 \%$ & $14,73 \%$ & $21,95 \%$ & $15,63 \%$ & $12,57 \%$ \\
\hline
\end{tabular}

Tabela A.12

Diferença entre a exigência de capital e as perdas que não excederam a exigência de capital - posição vendida multiplicadores 2 e 3 - em percentual do valor da carteira

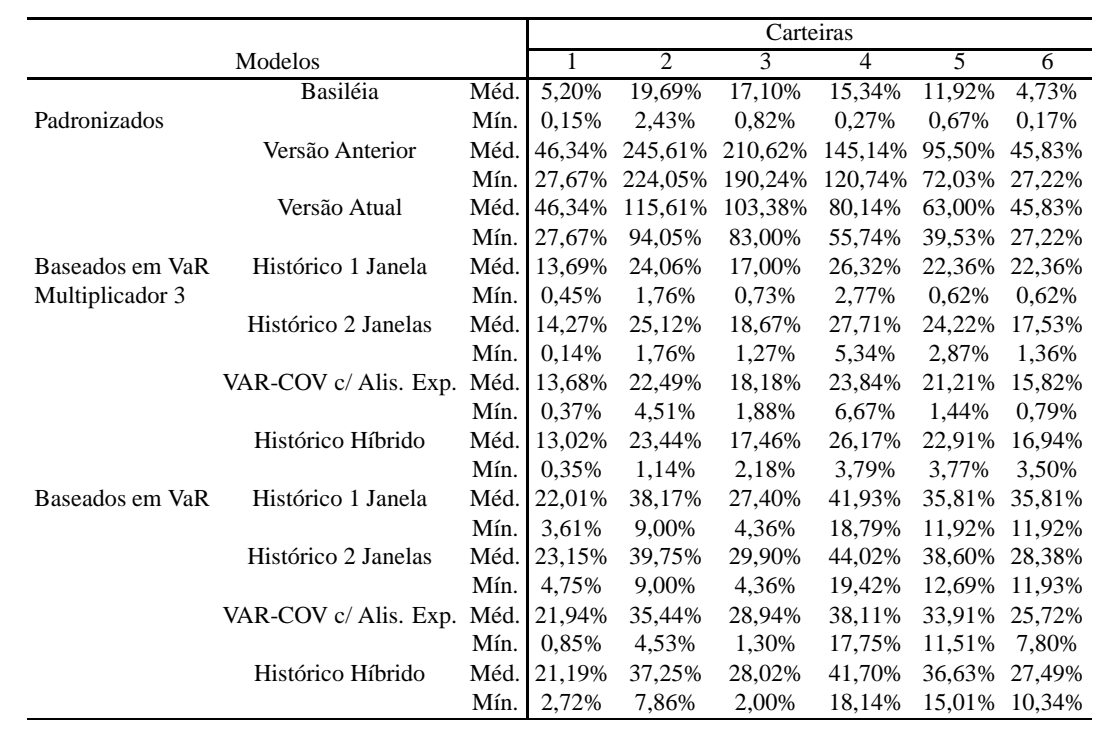




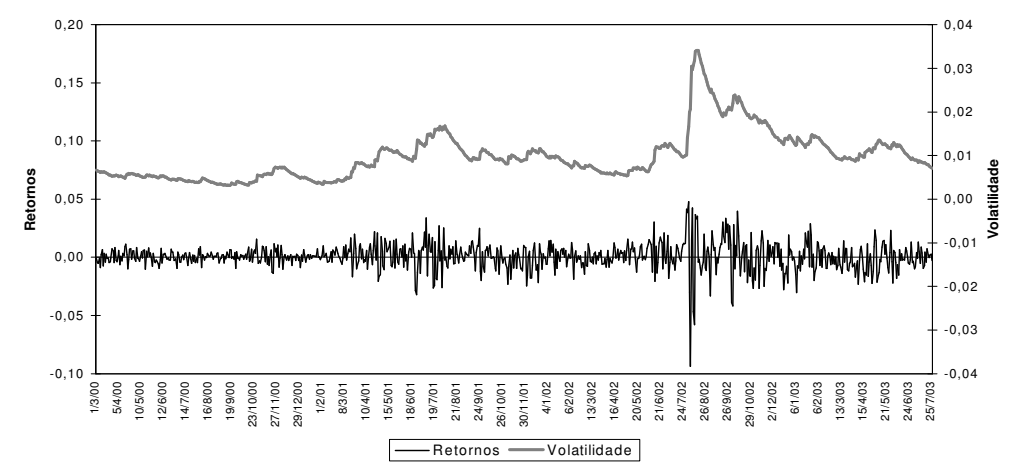

Figura A.1

Volatilidade dos retornos do Dólar Americano cotado em Reais, calculada por alisamento exponencial $(\lambda=0,94)$, de $01 / 03 / 2000$ a $25 / 07 / 2003$

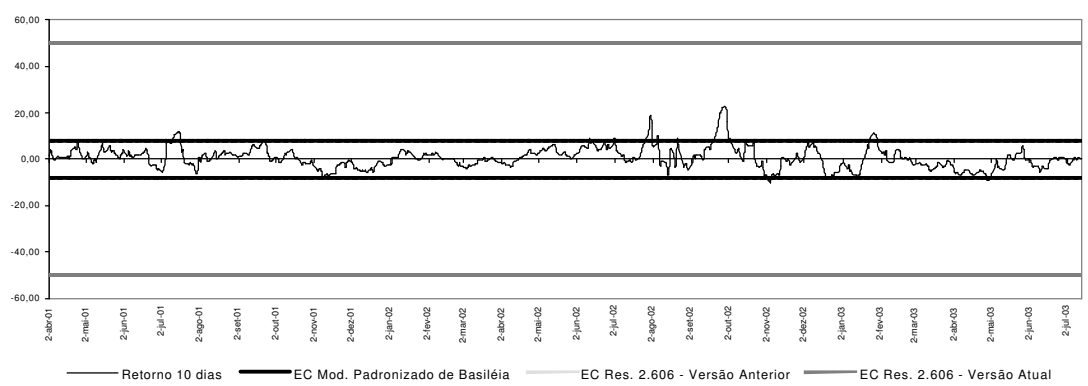

Figura A.2

Backtest de exigência de capital $(E C)$ para os modelos de abordagem padronizada - carteira

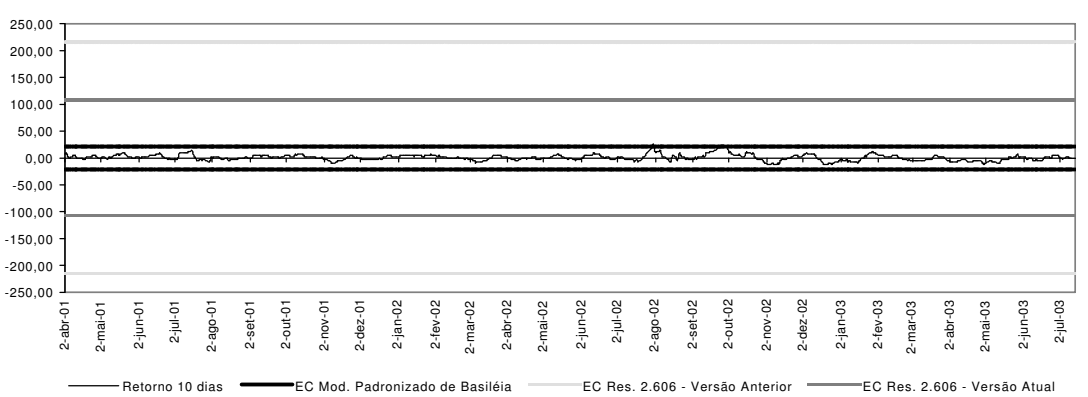

Figura A.3

Backtest de exigência de capital $(E C)$ para os modelos de abordagem padronizada - carteira 3 


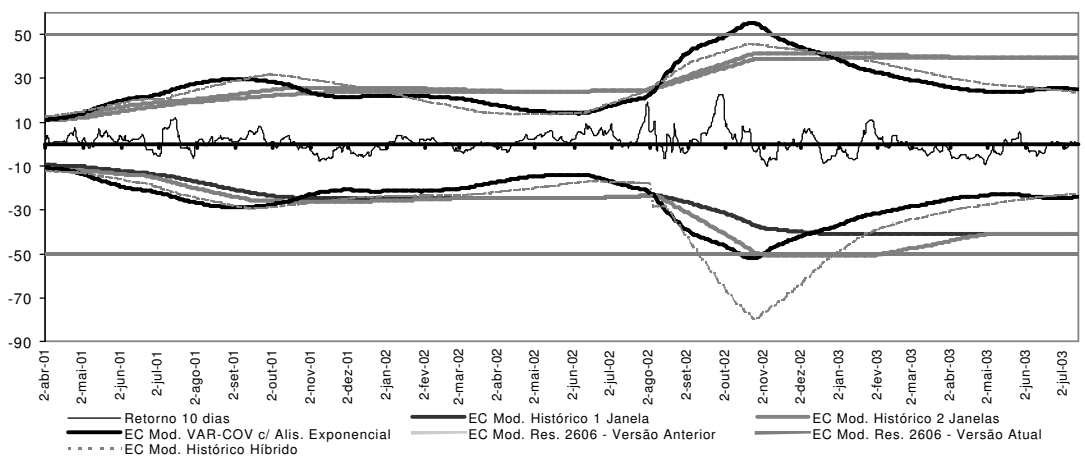

Figura A.4

Backtest de exigência de capital $(E C)$ para o modelo da resolução 2.606 e para os modelos baseados em VaR com multiplicador 3 - carteira 1

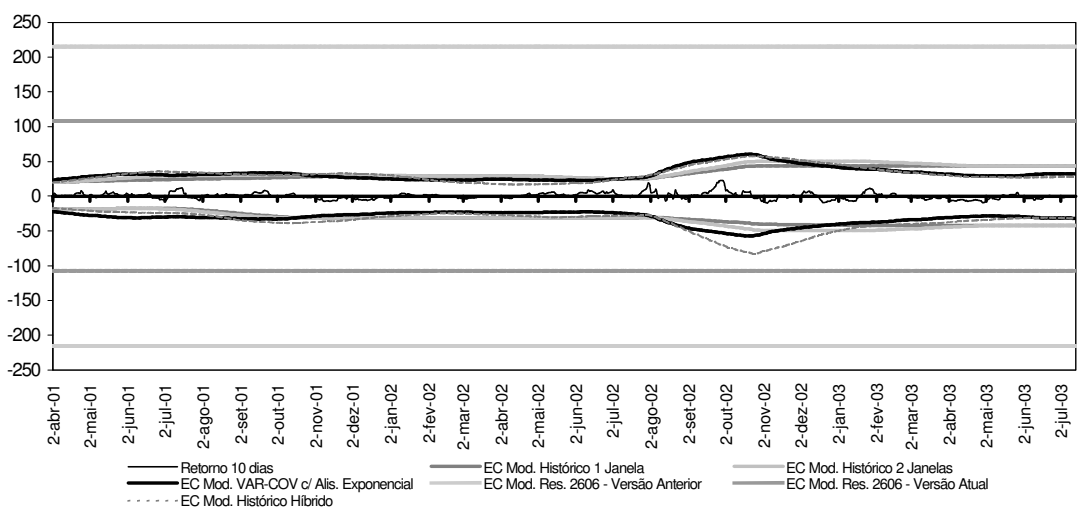

Figura A.5

Backtest de exigência de capital $(E C)$ para o modelo da resolução 2.606 e para os modelos baseados em VaR com multiplicador 3 - carteira 3 